\title{
The need for primary quality control of commercially available immunoassay kits
}

\author{
T Hashimoto, F Matsubara
}

\begin{abstract}
Discrepancies among three commercially available luteinising hormone (LH) radioimmunoassay RIA kits, all calibrated against the second-IRP-HMG (World Health Organisation International Laboratory for Biological Standards), were observed.

Even though the Japan Radioisotope Association carries out external quality control in Japan every year, inaccuracies still exist. This problem also exists elsewhere, and it is proposed that a global monitoring system of primary quality control (PQC) should be introduced by a body such as the World Health Organisation.
\end{abstract}

In laboratory science and clinical chemistry there are no doubts about the importance of internal and external quality control (IQC, EQC) for maintaining high standards in the laboratory.

There is now a need for primary quality control (PQC) both nationally and internationally; it is important for ensuring the accuracy of results. PQC means including the tests run by the manufacturers before they market their product to ensure quality and post-marketing checks to make sure the quality is maintained (fig 1). ${ }^{1}$ Although every company operates its own PQC system it is our experience that there are often imperfections and the products do not always come up to scratch.

In 1982 and 1983 Shishiba et al reported variations in the results obtained with insulin RIA kits, arising from the standards used, and showed that the technical skill of the user was not a major factor; the inaccurate results reflected the differences in the reference standards. $^{2}$ They emphasised the importance of establishing international standards which have since been adopted.

In 1986 the Japan Radioisotope Association (JRA) carried out its eighth quality control survey on luteinising hormone RIA kits. This survey showed that there was a large variation between the Daiichi RIA kit (Daiichi RI Co., Tokyo, Japan) which showed a spuriously high result and the EIKEN (EIKEN ICL. Co., Tokyo, Japan) and Amerlex (Amersham, UK) kits. The mean (SDs) were as follows: 89.5 (6.5); 66.0 (3.9); and $60 \cdot 1$ (4.1) IU/1, respectively $(p<0.001$ ) (fig 1$)$. The luteinising hormone reference standard of these three kits was calibrated against that of the second

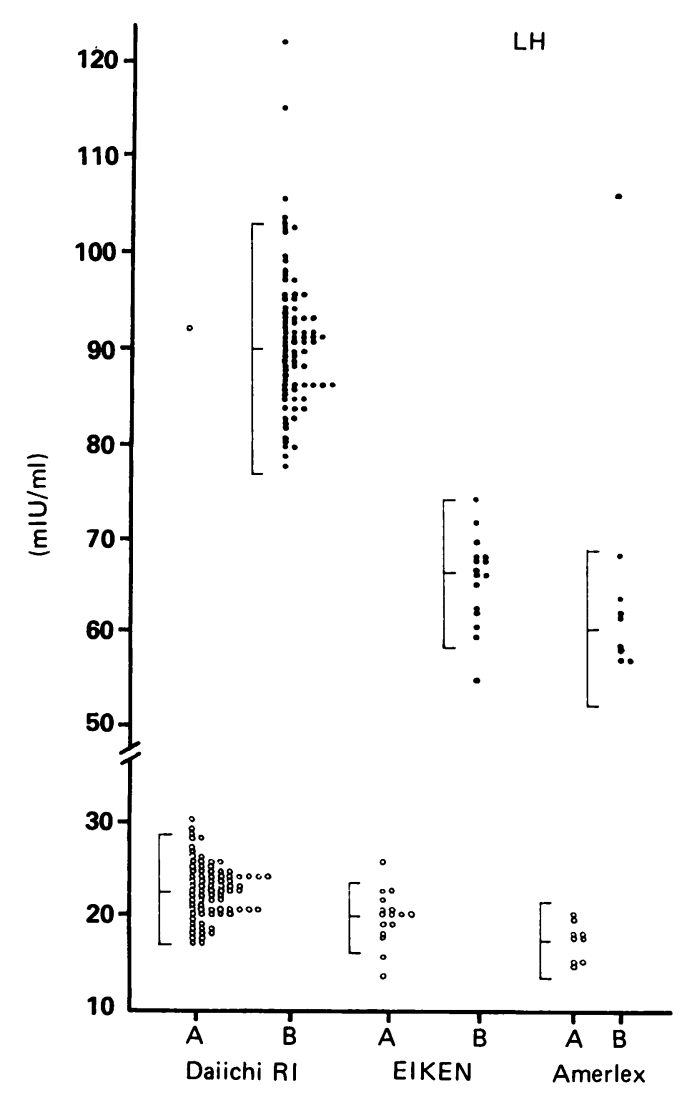

Figure 1 Results of luteinising hormone $(\mathrm{LH})$ radioimmunoassay in the eighth quality control survey carried out by the Japan Radioisotope Association (Adapted from P E Hall's model of quality control of RIAs).'

IRP-HMG (World Health Organisation International Laboratory for Biological Standards). The variation of the results, due to a difference in standards, was therefore disproved. The same reference standard (calibrated against the second IRP-HMG) was used in each kit and was therefore not the reason for the discrepancy. We must therefore assume that the incorrect calibration in the Daiichi RI kit caused the inaccurate results. There have been many unusual case reports in Japan related to the use of the Daiichi RI kit such as patients with normal basal luteinising hormone concentrations who do not respond to the GnRH test (Hashimoto T, Nishibu M, Matsubara F, unpublished observations). In 1988 Daiichi RI Co. stopped producing this kit and have now introduced a new one. 
Figure 2 System of quality control-Nature of primary, internal, and external quality control $(P Q C, I Q C$, and $E Q C)$.

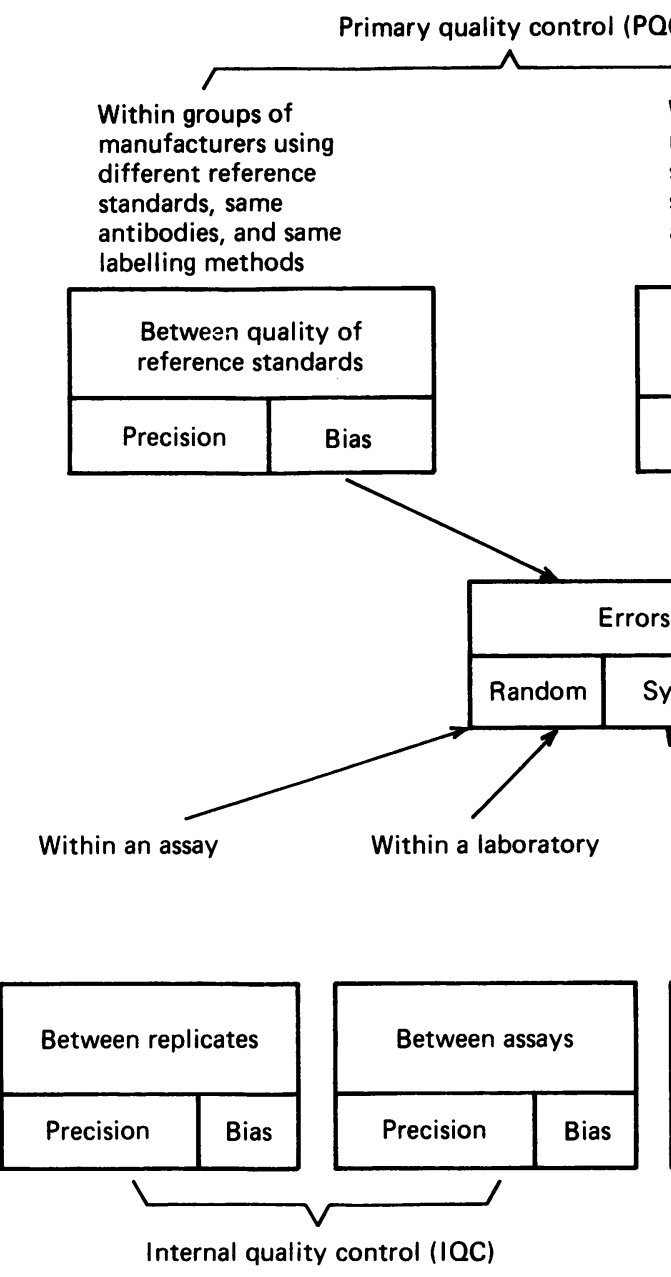

\section{Discussion}

The problems that we highlight here are well recognised. In 1988 Mahadevan and Ooi reported inherent changes in the free thyroxin $\left(\mathrm{FT}_{4}\right)$ values of $\mathrm{FT}_{4}$ clinical assay kits obtained from Dade, Baxter Travenol Diagnostic Inc, USA, between lot No 5695 and 5892 , the latter of which had been stabilised. ${ }^{3}$ They are continuing to monitor closely the performance of this assay for any further changes.

Even when using monoclonal antibody for immunoassay, normally considered to be more accurate, several researchers have reported interference from circulating antibodies in human serum samples in immunoassay procedures. Two-site immunometric assays are particularly prone to interference by antibodies, because any agent capable of cross-linking the labelled antibody with the antibody on the solid phase can generate a false positive signal in the absence of antigen. ${ }^{45}$ We have confirmed that false positive values can occur, depending on how the monoclonal antibody is labelled or otherwise treated in the assay of CA125 (Fujirebio Co., Tokyo, Japan). ${ }^{6}$ Use of an Inodogen labelled monoclonal antibody OC125 tracer considerably improved the Fujirebio Kit, as suggested by Klug et al. ${ }^{5}$

It is clear from these examples that higher quality products could have prevented these
Within groups of

manufacturers using

same reference

standard, different

antibodies, and different

labelling methods

Between quality of antibodies and labelling methods

\begin{tabular}{|l|l|}
\hline Precision & Bias \\
\hline
\end{tabular}

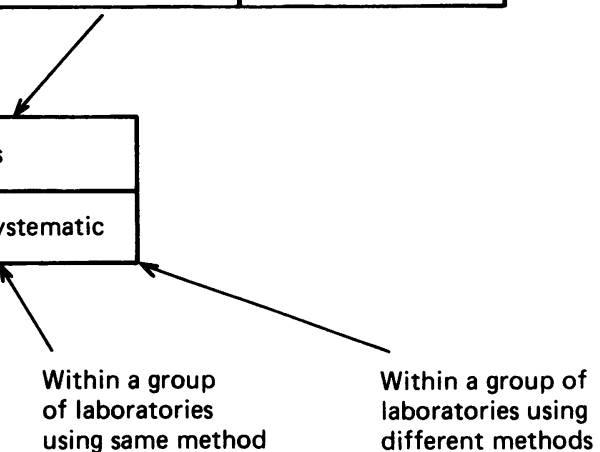

using same method

different methods

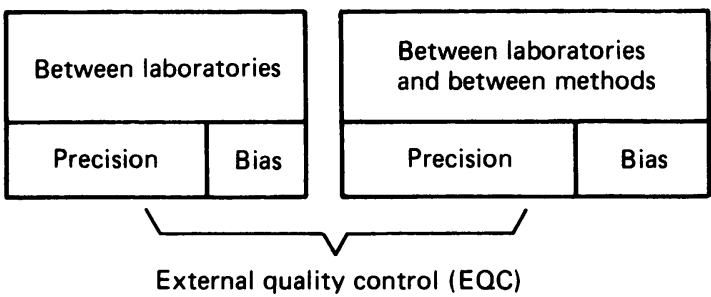

discordant results. Over the past decade numerous papers have been published on the erroneous test results obtained from commercially available kits. ${ }^{78}$ We suggest that monitoring bodies such as The World Health Organisation extend their brief from setting standards to also monitoring IQC, EQC, and $P Q C$, and that they publish an annual compilation of concise information, as a guide for users, in the form of a year book.

Given the high standard of practice required from technicians in IQC and EQC, it follows that we should demand the same high quality from the products we use. In fig 2 we have extended Dr Hall's system of quality control $^{1}$ to include PQC, which, in our view, is the highest priority.

We thank Mrs Tsuyuji Yoshimoto and Mrs Emi Yokoyama for their excellent secretarial assistance and Miss Hermione Elliot for her help in the preparation of this manuscript. This work was supported in part by the Japanese Clinical Pathology Foundation for International Exchange and the Clinical Pathology Foundation of Japan.

1 Hall PE. Round-table discussion on assay design, standardzation and within-laboratory quality control In: Radioimmunoassay and related procedures in medicine Vol 2 Vienna, Austria: IAEA, 1978:3-5.

2 Shishiba $\mathrm{Y}$, Irie $\mathrm{M}$, Yamada $\mathrm{H}$, et al. An inter- and intralaboratory quality-control survey of radioimmunointralaboratory quality-control survey of radioimmunoassay of insulin, thyroxin, thyrotropin, cortisol, digoxin, gastrin, $\beta_{2}$-microglobulin, and IgE in Japan with 
3 Mahadevan MS, Ooi DS. Changes in free thyroxin (FT 4 values of clinical assays gammacoat two-step assay. Clin Chem 1988;34:987.

4 Hunter WM, Budo PS. Circulating antibodies to ovine and bovine immunoglobulin in healthy subjects: a hazard for immunoassays. Lancet 1980;ii:1136.

5 Klug TL, Green PJ, Zurawski VR, Davis HM. Confirmation of a false-positive result in CA125 immunoradiometric assay caused by human anti-idiotypic immunoglobulin. Clin Chem 1988;34:1071-6.
6 Hashimoto T, Ohba N, Matubara F. Discordant CA125 measurements in normal healthy women. Clin Chem 1990; 36:1377-8.

7 Banfi G, Casari E, Murone M, Bonini P. Discrepancies among commercial kits for assaying growth hormone. Clin Chem 1990;36:402.

8 Smith MC, Brown ME, Morel JH, Woodward SC. Erroneous test results obtained with the Tandem-E TSH kit. Clin Chem 1988;34:1946-7.

\title{
Helicobacter pylori serology using specimens collected on filter paper
}

\author{
Z Huang, B Dwyer, J Kaldor
}

\begin{abstract}
A simple method for the collection of blood specimens on filter paper for serology of Helicobacter pylori was devised. Blood was freshly applied to small Whatman $3 \mathrm{~mm}$ filter paper and allowed to dry. Serological activity, as measured by reactivity to $H$ pylori antigens (AMRAD, Australia), was retained after storage for one month at both room temperature and at $4^{\circ} \mathrm{C}$. This technique eliminates formal venepuncture, separation of sera, and arduous packaging of specimens to be sent to the laboratory.
\end{abstract}

Seroepidemiological surveys are often rendered more difficult because of a lack of facilities for the collection and transportation of liquid serum specimens and because of difficulties with venepuncture, especially in infants. Specimen samples collected and dried on filter paper overcome these disadvantages and require only a minute volume of specimen, easily collected directly from an ear lobe or finger prick.

Samples collected and dried on filter paper have been used for the detection of markers of hepatitis B. $^{1}$ phenylketonuria, ${ }^{2}$ separation of haemoglobin $\mathrm{S},{ }^{3}$ detection of antibodies to human immunodeficiency virus, ${ }^{4}$ and the storage of cerebrospinal fluid. ${ }^{5}$

\section{Methods}

Samples from 20 patients ( 10 infected patients and 10 non-infected patients), assessed by endoscopy, histology, Gram stain and culture were used to define the conditions of testing for comparison of conventional liquid serum tests and tests on specimens dried on filter paper. The samples were allowed to dry completely at room temperature and then stored in plastic bags (figure). Aliquots of fresh samples were applied in volumes of $10 \mu \mathrm{l}$ (serum) and $20 \mu \mathrm{l}$ (whole blood) to strips of filter paper.

Whatman $3 \mathrm{~mm}$ filter paper (No 3030917) was used. The filter paper was cut into $40 \mathrm{~mm}$ $\times 5 \mathrm{~mm}$ strips; one end of each strip was used for identification and the other was used for the specimen. For this experiment one lot of the filter paper dried specimens was kept at $4^{\circ} \mathrm{C}$ and the other at room temperature $\left(22^{\circ} \mathrm{C}\right)$. The stability of antibody titre in the dried specimens was tested at weekly intervals for four weeks. The results were compared with those obtained from a collection of multiple aliquots of the same serum kept at $-70^{\circ} \mathrm{C}$ until thawed on the day of testing.

Statistical comparison was made using paired $t$ tests, the Wilcoxon sign test, the Mann-Whitney $U$ test and one way analysis of variance.

Specimens from 83 healthy people enrolled in a seroepidemiological study of rickettsial

\begin{tabular}{|c|c|c|c|c|c|c|c|c|}
\hline \multirow[b]{3}{*}{$\begin{array}{l}\text { Mean negative } 15 \text { days } \\
\text { Mean negative } 30 \text { days } \\
\text { Mean positive } 15 \text { days } \\
\text { Mean positive } 30 \text { days }\end{array}$} & \multirow{2}{*}{$\begin{array}{l}\text { Control serum } \\
\text { specimens }\end{array}$} & \multicolumn{7}{|c|}{ Filter paper specimens } \\
\hline & & Serum $4^{\circ} \mathrm{C}$ & \multicolumn{2}{|c|}{ Serum $R T$} & \multicolumn{2}{|c|}{ Blood $4^{\circ} \mathrm{C}$} & \multicolumn{2}{|c|}{ Blood RT } \\
\hline & $\begin{array}{rr}1.0 & (0.3) \\
1.0 & (0.4) \\
11.4 & (3.9) \\
11.6 & (3.9)\end{array}$ & $\begin{array}{rr}1.0 & (0.4) \\
0.8 & (0.3) \\
11.3 & (4.4) \\
11.0 & (3.7)\end{array}$ & $\begin{array}{r}0.9 \\
1.0 \\
12 \cdot 4 \\
8.9\end{array}$ & $\begin{array}{l}(0 \cdot 3) \\
(0 \cdot 3) \\
(4 \cdot 8) \\
(3 \cdot 6)\end{array}$ & $\begin{array}{r}1 \cdot 0 \\
1.0 \\
12 \cdot 4 \\
13 \cdot 7\end{array}$ & $\begin{array}{l}(0 \cdot 2) \\
(0 \cdot 4) \\
(4 \cdot 5) \\
(4 \cdot 6)\end{array}$ & $\begin{array}{r}0 \cdot 9 \\
1 \cdot 0 \\
12 \cdot 3 \\
13 \cdot 1\end{array}$ & $\begin{array}{l}(0 \cdot 3) \\
(0 \cdot 4) \\
(4 \cdot 3) \\
(4 \cdot 5)\end{array}$ \\
\hline
\end{tabular}

